\title{
Reading and reception of literary works among High School students.
}

\author{
Jefferson Cano (Prof. Dr.), Luísa Santoro Alvarenga (IC).
}

\begin{abstract}
According to the Reception Aesthetics, literature would also result from constant interaction between reader, author and work, based on historical, social and cultural factors - which influence the appreciation of the literary work by the reading public. The qualitative analysis aims to identify behaviors or opinions in a specific social parcel, generating accurate and detailed results. The quantitative approach, on the other hand, seeks to obtain generalized information, numerically measuring the characteristics of the discussed problematic. The research goal is to collect qualitative and quantitative data about the reading activity from interviews and questionnaires with high school students as well as analyze the results based on the principles of Reception Aesthetics.
\end{abstract}

Key words: Reception Aesthetics, Reading, High School.

\section{Introduction}

The Reception Aesthetics presupposes that the legitimacy of a literary work lies on its reader and on his analysis and interpretation ${ }^{1}$, being influenced by the historical and social context in which they belong.

Following this premise, one must place the literary text on its historical background to understand it fully. It is also important to highlight the reader's analysis and his reaction to the work, which consists of an evaluation of the aesthetic value of the text. Thus, one can notice the transitory nature of the literary work, since its meaning is constantly updated by the reader and the criticism.

Within the scope of data collection, there is qualitative and quantitative research. The first method aims to investigate the potential presence of a quality, focusing on the interviewee. The second aims to obtain numerical measures on the quality observed in a studied group ${ }^{2}$.

\section{Results and Discussion}

Interviews were conducted with 20 students and were documented in audio for later analysis. Open questions were prioritized in order to enable the identification of a reader profile as well as the literary works read by the students.

There were also printed questionnaires that were delivered to 123 students. The questions had restrictive nature that aimed numerical data collection.

From the results obtained with the two types of research, it was decided to conduct the triangulation technique - junction of qualitative and quantitative methods, validating the data collected in both surveys.

\section{Conclusions}

It was found that most high school students questioned are interested in reading literary texts, reading works outside the lists provided by the "vestibulares" (equivalent to SATs). Furthermore, the concept of literary genre proved not to be understood by the students.

As for preferences, there was a predilection for young adult novels such as "Paper Towns" by John Green - the most cited work among the teenagers.

\section{Acknowledgement}

I thank PIBIC and CNPq for the opportunity. I also thank my supervisor, Jefferson Cano for his help and patience as well as the Colégio Objetivo Pirassununga, for enabling the realization of fieldwork. Finally, I thank my family and boyfriend for their support.

\footnotetext{
JAUSS, Hans Robert. A história da literatura como provocação a teoria literária. São Paulo, SP: Ática, 1994.

${ }^{2}$ TRUJILLO, Victor. Pesquisa de mercado qualitativa e quantitativa. São Paulo, SP : Scortecci, 2001.
} 